\title{
A population-based study of the associations between neighbourhood walkability and different types of physical activity in Canadian men and women
}

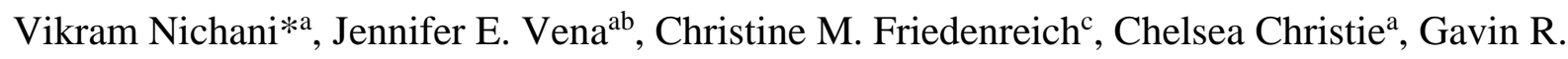
McCormack $^{\mathrm{a}}$

${ }^{\mathrm{a} D e p a r t m e n t}$ of Community Health Sciences, Cumming School of Medicine, University of Calgary, TRW $3^{\text {rd }}$ floor, 3280 Hospital Drive NW Calgary, Alberta T2N 4Z6, Canada

${ }^{b}$ CancerControl Alberta, Alberta Health Services, Richmond Road Diagnostic and Treatment Centre, 1820 Richmond Road SW Calgary, Alberta T2T 5C7, Canada

${ }^{\mathrm{c}}$ Department of Cancer Epidemiology and Prevention Research, CancerControl Alberta, Alberta Health Services, $22102^{\text {nd }}$ St SW Calgary, Alberta T2S 3C3, Canada; Department of Community Health Sciences and Department of Oncology, Cumming School of Medicine, University of Calgary, TRW $3^{\text {rd }}$ floor, 3280 Hospital Drive NW Calgary, Alberta T2N 4Z6, Canada

Abbreviations: ATP: Alberta's Tomorrow Project, $\alpha$ : Cronbach's alpha, $\beta$ : Beta Coefficient, CI: Confidence Interval, HLQ: Health and Lifestyle Questionnaire, IPAQ: International Physical Activity Questionnaire, LW: Leisure Walking, MPA: Moderate-intensity Physical Activity, NEWS-A: Neighbourhood Environment Walkability Scale-Abbreviated Version, OR: Odds Ratio, SD: Standard Deviation, TW: Transporation Walking, USA: United States of America, VPA: Vigorous-intensity Physical Activity

Email addresses: vikram.nichani@ucalgary.ca (V.Nichani), jennifer.vena@albertahealthservices.ca (J.Vena), christine.friedenreich@ahs.ca (C.Friedenreich), chelsea.christie1@ucalgary.ca (C.Christie), gavin.mccormack@ucalgary.ca (G. McCormack)

Corresponding Author*: Vikram Nichani, Department of Community Health Sciences, Cumming School of Medicine, University of Calgary, TRW $3^{\text {rd }}$ floor, 3280 Hospital Drive NW Calgary, Alberta T2N 4Z6, Canada, Telephone:1-403-210-3807, Emailvikram.nichani@ucalgary.ca

Word count: Abstract (247); main text excluding abstract, tables, and references (4368); references (55); Table count: 5 


\section{ABSTRACT}

Few Canadian studies have examined whether or not associations between neighbourhood walkability and physical activity differ by sex. We estimated associations between perceived neighbourhood walkability and physical activity among Canadian men and women. This study included cross-sectional survey data from participants in 'Alberta's Tomorrow Project' (Canada; $\mathrm{n}=14,078$ ), a longitudinal cohort study. The survey included socio-demographic items as well as the International Physical Activity Questionnaire (IPAQ) and the abbreviated Neighbourhood Environment Walkability Scale (NEWS-A), which captured perceived neighbourhood built characteristics. We computed subscale and overall walkability scores from NEWS-A responses. Covariate-adjusted generalized linear models estimated the associations of participation $(\geq 10$ minutes/week) and minutes of different types of physical activity, including transportation walking (TW), leisure walking (LW), moderate-intensity physical activity (MPA), and vigorous-intensity physical activity (VPA) with walkability scores. Walkability was positively associated with participation in TW, LW, MPA and VPA and minutes of TW, LW, and VPA. Among men, a negative association was found between street connectivity and VPA participation. Additionally, crime safety was negatively associated with VPA minutes among men. Among women, pedestrian infrastructure was positively associated with LW participation and overall walkability was positively associated with VPA minutes. Notably, overall walkability was positively associated with LW participation among men and women. Different perceived neighbourhood walkability characteristics might be associated with participation and time spent in different types of physical activity among men and women living in Alberta. Interventions designed to modify perceptions of neighbourhood walkability might influence initiation or maintenance of different types of physical activity.

Keywords: neighbourhood, walkability, physical activity, built environment, walking 


\section{INTRODUCTION}

Creating a supportive neighbourhood built environment may be one strategy for increasing physical activity at the population level. Walkable neighbourhoods are characterized by the presence of characteristics that support physical activity such as high residential density, mix and diversity of land uses and destinations, high street connectivity, pedestrian infrastructure, traffic and crime safety, and aesthetics (Cerin et al., 2014; Kerr et al., 2016). Studies have found associations between perceived and objectively measured built environment characteristics and physical activity in adults (Jack and McCormack, 2014; Zhou et al., 2013). More positive perceptions of neighbourhood walkability may be particularly important in terms of encouraging physical activity among adults in Canada (Jack and McCormack, 2014) and elsewhere (Adlakha et al., 2018; Bergman et al., 2009; Brownson et al., 2001; Cerin et al., 2007; Ding et al., 2013; Evenson et al., 2012; Hoehner et al., 2005; Jáuregui et al., 2016; Jáuregui et al., 2017; Kamada et al., 2009; Malambo et al., 2017). A meta-analysis found perceived presence of physical activity facilities, sidewalks, shops and services at walking distance, and traffic safety to be positively associated with physical activity in adults (Duncan et al., 2005). A multi-country study (not including Canadian data) found several perceived neighbourhood characteristics (e.g., residential density, land use mix access, land use mix diversity, street connectivity, traffic safety, crime safety, and aesthetics) were similarly associated with transportation walking, leisure walking, or moderate-to-vigorous intensity physical activity (Cerin et al., 2014; Cerin et al., 2018; Christiansen et al., 2016; Kerr et al., 2016; Sallis et al., 2016; Sugiyama et al., 2014). Recently, Farkas et al. (2019) undertook a systematic review of 25 Canadian studies that had investigated relations between objectively-measured built environment and walking. They found overall walkability and land use were consistently associated with transportation walking. Additionally, proximity to destinations was associated with walking for any purpose (Farkas et al., 2019). Inconsistent evidence existed linking the built environment with leisure walking (Farkas et al., 2019).

Women are 6-10\% less physically active than men (Guthold et al., 2018; Hands, 2016), as determined by overall physical activity. Evidence suggests the importance of some perceived neighbourhood characteristics for supporting physical activity may differ for men and women (Jáuregui et al., 2016; Pelclová et al., 2014; Spence et al., 2006; Van Dyck et al., 2012; Van Dyck et al., 2013; Van Dyck et al., 2015). The associations between overall walkability and minutes of 
transportation walking are found to be stronger in women than men (Van Dyck et al., 2012). In a Czech Republic study, participation in transportation walking was associated with self-reported street connectivity and traffic/crime safety among men and land use mix diversity and aesthetics among women (Pelclová et al., 2014). In a Canadian study, Spence et al. (2006) also found associations between self-reported interesting scenery and presence of many places to visit within easy walking distance from home and participation in walking among women only. Notably, general as well as sex-specific differences in associations between the perceived walkability and physical activity may depend on the type of physical activity examined (e.g., walking, moderateintensity, and vigorous-intensity) (Malambo et al., 2017; Pelclová et al., 2014). In addition, perceptions of neighbourhood walkability are consistently associated with transportation walking, but appear less consistently associated with other types of physical activity (Wendel-Vos et al., 2007).

Walking is the most frequently reported form of physical activity undertaken by the adults (Shifan et al., 2015). However, a small proportion of adults participate in other moderate-intensity and vigorous-intensity physical activities (Shifan et al., 2015). Other than transportation walking, there is a dearth of evidence on sex-specific associations between neighbourhood walkability and different types of physical activity (Pelclová et al., 2014; Spence et al., 2006; Van Dyck et al., 2012; Van Dyck et al., 2013; Van Dyck et al., 2015). This evidence is important however, for planning physical activity interventions especially those intended to increase moderate-intensity and vigorous-intensity physical activity participation and or duration equally for men and women.

Thus, the objectives of this study were to: 1) estimate the associations between perceived neighbourhood built characteristics as measured by walkability subscales and overall walkability and different physical activities including transportation walking, leisure walking, leisure moderate-intensity physical activity, and leisure vigorous-intensity physical activity, and; 2) estimate sex-related effect modification of these associations between walkability and physical activity. 


\section{METHODS}

\section{Data source: Alberta's Tomorrow Project}

Data for this study was collected in Alberta, Canada. Alberta is a province with a large geographical area $\left(662,583 \mathrm{~km}^{2}\right)$ with urban areas spread throughout. Some urban areas, like Calgary are located in the foothills of the Rocky Mountains and so have some hills, whereas other urban areas like Edmonton, Red Deer, Lethbridge are essentially located in the prairies where the topography is relatively flat (Alberta-Parks, 2015; Canada-Guide, 2019). Similar to many other North American cities, urban areas in Alberta historically have been planned and developed to facilitate automobile movement. Moreover, evidence suggests that in Calgary (Alberta), physical activity patterns are associated with season (McCormack et al., 2010). On average, annually, Alberta receives sunshine for a period of 312 days, average daily temperatures during summer range from 20 to 25 degree Celsius, and average daily temperatures during winter range from -5 to -15 degree Celsius (Travel-Alberta, 2019). In Alberta, on average, annual precipitation varies from 30 to 60 centimetres (12 to 24 inches) including rain, sleet, and snow (Travel-Alberta, 2019).

Our study involved a secondary analysis of data from Alberta's Tomorrow Project (ATP), a longitudinal cohort study of Albertan adults investigating the etiologic factors of cancer and chronic disease (Robson et al., 2016; Ye et al., 2017). The design and methods of the cohort have been published previously (Robson et al., 2016; Ye et al., 2017). Briefly, from 2000 to 2008 urban and rural households $(n=63,486)$ were contacted using random digit dialling to recruit study participants aged 35-69 years, who were proficient in the English language, had no medical history of cancer besides non-melanoma skin cancer, and were not intending to leave Alberta in the following year (Robson et al., 2016; Ye et al., 2017). Eligible participants were mailed a consent form and a baseline health and lifestyle questionnaire (HLQ). In 2008, participants were invited to complete a follow-up HLQ. The follow-up HLQ collected updated information on sociodemographic characteristics, personal and family health history, and a variety of health and lifestyle behaviours, and quantified new information on additional health and lifestyle behaviours and influences, including physical activity and the built environment (Robson et al., 2016). 
This study analyzes cross-sectional data from the 2008 follow-up, including socio-demographic, physical activity and built environment data captured from participants enrolled in ATP between 2000-2008, who completed the 2008 follow-up HLQ, and resided in urban settings determined from their six-digit residential postal code by using second digit in the postal code $(n=15,342)$. Note that Canada Post classifies a Canadian postal code as 'rural' if the second digit is 0 (e.g., T012A2) or 'urban' if the second digit is a number that ranges from 1 to 9 (e.g., T1H2A2) (StatCan, 2003). According to the recent data on population density, more than 6.3 million Canadians are living in rural areas (Stat-Can, 2018). The population density of rural Canada is <400 people per square kilometre (Stat-Can, 2018). The University of Calgary Conjoint Health Research Ethics Board approved this analysis from the ATP cohort study.

\section{Variables}

\section{Perceived neighbourhood walkability}

The abbreviated Neighbourhood Environment Walkability Scale (NEWS-A), a reliable and validated self-report instrument, captured perceptions of neighbourhood walkability (Cerin et al., 2006). The ATP dataset included 54 NEWS-A items that represented 11 subscales including residential density (e.g., single-family homes, town houses, condominiums; six items), land use mix diversity (e.g., destinations within walking distance; 20 items) land use mix access (e.g., ease of walking to destinations; three items), street connectivity (e.g., intersection density, routes; three items), pedestrian infrastructure (e.g., sidewalks, lighting, crosswalks; six items), aesthetics (e.g., trees, natural sights; four items), traffic safety (e.g., driver speed, traffic volume; three items), crime safety (e.g., daytime and nighttime walking safety; three items), hilliness (hilly streets; one item), physical barriers (major barriers to walking; one item), and lack of parking at shopping areas (difficulty in parking in shopping areas; one item). Excluding residential density and land use mix diversity subscale items, all items were scored on a four-point Likert scale (strongly disagree to strongly agree). Residential density items were scored on a five-point Likert scale (none to all) and land use mix diversity items scored on a five-point scale (>30, 21 to 30, 11 to 20, 6 to 10 , or 1 to 5 minutes). Some items were reversed scored so that higher scores represented higher walkability (e.g., hilliness, physical barriers, or crime safety). Informed by previous NEWS-A scoring algorithms (Sallis, 2011), we estimated a participant average value for each multi-item 
subscale. Consistent with previous studies (De Bourdeaudhuij et al., 2015; Van Dyck et al., 2012), subscale scores were converted to z-scores and summed to estimate an overall walkability score for each participant. Internal consistency (Cronbach's alpha; $\alpha$ ) of the multi-item subscales ranged from $\alpha=0.44$ (street connectivity) to $\alpha=0.94$ (land use mix diversity) and was $\alpha=0.94$ for overall walkability.

\section{Physical activity participation and minutes}

The ATP 2008 follow-up HLQ captured self-reported physical activity using the International Physical Activity Questionnaire (IPAQ) Long Form (Robson et al., 2016). The IPAQ provides reliable and valid estimates of physical activity (Craig et al., 2003). The questions on participation in different types of physical activity were framed as follows: 1) "During the last 7 days, on how many days did you walk for at least 10 minutes at a time to go from place to place?" (transportation walking [TW]), 2) "During the last 7 days, on how many days did you walk for at least 10 minutes at a time in your leisure time?" (leisure walking $[\mathrm{LW}]$ ), 3) "During the last 7 days, on how many days did you do moderate physical activities like bicycling at a regular pace, swimming at a regular

pace, and double tennis in your leisure time?" (moderate physical activity [MPA]), and 4) "During the last 7 days, on how many days did you do vigorous physical activities like aerobics, running, fast bicycling, or fast swimming in your leisure time?" (vigorous physical activity [VPA]) (ATP, 2018). Those who reported at least one day of participation ( $\geq 10$ minutes) then reported their usual time per day undertaking the physical activity. The reported frequency (days) of participation and usual minutes per day were used to estimate minutes of physical activity during the last 7 days. For the analysis presented here, we included data on transportation (walking only) and leisure domains (walking, MPA, and VPA) from the IPAQ.

\section{Socio-demographic characteristics}

Informed by previous research, and based on their availability in the ATP dataset, our analysis included the covariates age, sex, self-reported health, marital status, number of children in household, highest education level, employment status, household income, and season participant returned the HLQ (Lounassalo et al., 2019; Tucker and Gilliland, 2007). Sex was also used as an 
effect modifier. Considering the weather patterns in Canada, it is important to consider season as a covariate while determining the associations between neighbourhood walkability and physical activity.

\section{Statistical analyses}

The proportion of missing data for our variables of interest was low $(8 \%)$ therefore, we performed a complete case analysis. We estimated descriptive statistics for socio-demographic characteristics, neighbourhood walkability, and physical activity. To estimate the covariateadjusted odds ratios (ORs) and 95 percent confidence intervals (95\% CIs) for the association between walkability (subscales and overall) and participation in each physical activity separately, we used a generalized linear model with a binomial distribution and logit link function. To estimate the covariate-adjusted slope coefficients ( $\beta$ s) and 95\% CIs for the association between walkability and duration of each physical activity, we used a generalized linear model. Note that participants who reported no participation in each activity (i.e., those reporting <10 minutes of physical activity) were excluded from the duration outcome analysis. To avoid model collinearity among the subscales, we only tested one walkability subscale at a time. We converted walkability subscales to z-scores prior to analysis. We tested sex as an effect modifier of the association of overall walkability and each walkability subscale with each physical activity outcome. A p-value $<0.05$ was considered statistically significant for main and interaction effects. Statistical analysis was undertaking using Stata Version 15 (Stata Corp LLC, Texas, USA).

\section{RESULTS}

\section{Descriptive statistics for the entire cohort}

Complete data for our analysis was available for 14,078 participants. The sample mean age was $55.0(\mathrm{SD}=9.1)$ years. Approximately $62 \%$ of our sample was female, $8 \%$ reported as poor or fair health, $6 \%$ were single, $73 \%$ reported no children currently living in the household, $13 \%$ had completed some or entire university postgraduate degree, 69\% were part-time or full-time employed, and 10\% reported household incomes $\geq \$ 200,000 /$ year (Table 1). Most participants perceived their neighbourhoods to have low residential density (Table 2). Conversely, most 
participants perceived their neighbourhoods to have high aesthetics, crime safety, but also hilly streets and physical barriers (Table 2). Approximately $61 \%$ of participants participated in TW or LW, $29 \%$ in MPA, and 33\% in VPA (Table 3).

\section{Associations between walkability and physical activity (pooled analysis)}

Adjusting for covariates, overall walkability was positively associated with participation in TW (OR 1.05; 95\% CI 1.04, 1.06), LW (OR 1.03; 95\% CI 1.02, 1.04), MPA (OR 1.02; 95\% CI 1.01, 1.03), and VPA (OR 1.02; 95\% CI 1.01, 1.03) (Table 4). Moreover, adjusting for covariates, overall walkability was positively associated with weekly of minutes of TW ( $\beta 1.41 ; 95 \%$ CI 0.43 , 2.40), LW ( $\beta$ 1.01; 95\% CI 0.08, 1.94), VPA ( $\beta$ 1.37; 95\% CI 0.39, 2.35) but was not associated with weekly minutes of MPA $(\beta 0.61 ; 95 \%$ CI $-0.46,1.69)$ (Table 4$)$.

Among the 11 walkability subscales, residential density was positively associated with participation in TW and LW and minutes of TW and VPA, land use mix diversity was positively associated with participation in TW, LW, MPA, and VPA and minutes of VPA, and land use mix access was positively associated with participation in TW, LW, MPA, and VPA and minutes of TW and VPA. Street connectivity was positively associated with participation in TW. Pedestrian infrastructure was positively associated with participation in TW, LW, and VPA and minutes of VPA. Aesthetics was positively associated with participation in TW, LW, MPA, and VPA and positively associated with minutes of TW and LW (Table 4).

Traffic safety was negatively associated with participation in TW. Crime safety was negatively associated with participation in TW, but positively associated with participation in LW. Hilliness and physical barriers were positively associated with minutes of LW. Lack of parking at shopping areas was positively associated with participation in TW and minutes of TW, MPA, and VPA. No other significant associations were found (Table 4). 


\section{Associations between walkability and physical activity (sex interaction analysis)}

We found evidence of sex modification for overall walkability and participation in LW (interaction p-value=0.012). In men and women, overall walkability was positively associated with participation in LW (men: OR 1.005; 95\% CI 1.002, 1.008; women: OR 1.009; 95\% CI 1.007, 1.01). For LW participation, we found significant interaction for sex and pedestrian infrastructure (interaction $\mathrm{p}$-value=0.048). In women, pedestrian infrastructure was positively associated with LW participation (OR 1.03; 95\% CI 1.02, 1.04). For MPA participation, we found significant interaction for sex and lack of parking at shopping areas (interaction p-value $=0.018$ ). However, in men and women, the associations of lack of parking at shopping areas with MPA participation were not statistically significant (men: OR 1.01; 95\% CI 0.99, 1.02; women: OR 0.99; 95\% CI 0.98, 1.002). For VPA participation, the interaction of sex and street connectivity was significant (interaction p-value=0.009). In men, street connectivity was negatively associated with VPA participation (OR 0.98; 95\% CI 0.97, 0.99) (Table 5).

For weekly minutes of VPA, significant interaction between sex and overall walkability was found (interaction $\mathrm{p}$-value $=0.042$ ). In women, overall walkability was positively associated with VPA minutes ( $\beta 2.05$; 95\% CI 0.94, 3.16). For weekly minutes of VPA, significant interaction between sex and crime safety was found (interaction p-value=0.046). In men, the association of crime safety with VPA minutes was statistically significant ( $\beta-10.58$; 95\% CI -19.69, -1.46). The interaction between sex and physical barriers for outcome of VPA minutes was also statistically significant (interaction $\mathrm{p}$-value $=0.040$ ). However, in men and women, the associations of physical barriers with VPA minutes were not statistically significant (men: $\beta-6.13$; 95\% CI -13.29, 1.03; women: $\beta$ 2.86; 95\% CI -1.92, 7.63) (Table 5).

\section{DISCUSSION}

Similar to previous studies (Van Dyck et al., 2012; Van Dyck et al., 2013), we found perceived neighbourhood walkability was associated with physical activity among adults. Specifically, we

found perceived neighbourhood walkability was associated with participation in TW, LW, MPA, 
VPA, and minutes of TW, LW, and VPA but not minutes of MPA. Notably, our findings demonstrate that perceptions of different neighbourhood built characteristics are likely associated with participation and/or time spent in different types of physical activity. In support of previous studies (Jáuregui et al., 2016; Pelclová et al., 2014; Spence et al., 2006; Van Dyck et al., 2012; Van Dyck et al., 2013; Van Dyck et al., 2015) we also found that some associations between perceived neighbourhood built characteristics and physical activity differ by sex. Pedestrian infrastructure was associated with LW participation only among women while street connectivity and crime safety were associated with vigorous physical activity (participation for street connectivity and minutes for crime safety) only among men. Overall walkability was associated with physical activity among men and women however, the relationship between overall walkability and LW was stronger for women and the relationship between overall walkability and minutes of VPA was only significant among women.

Similar to our findings, Van Dyck et al. (2012) found a positive association between overall walkability (constructed by aggregating residential density, land use mix access, proximity to destinations, and aesthetics into an index) and TW minutes. Van Dyck et al. (2013) also found positive associations between a 'recreational walking-friendliness' index (constructed by aggregating residential density, not many physical barriers, and aesthetics into an index) and LW minutes as well as a 'leisure-time activity friendliness' index (constructed by aggregating residential density, proximity to recreational facilities, walking and cycling facilities, and crime safety into an index) and minutes of moderate-to-vigorous physical activity. Recently, a Canadian systematic review found objectively-measured neighbourhood characteristics (e.g., overall walkability, land use, and proximity to destinations) were consistently associated with TW (Farkas et al., 2019). Our finding that overall walkability was associated with TW supports previous evidence of consistent associations between walkability and TW (Wendel-Vos et al., 2007). Our findings also suggest perceptions of walkability might also be associated with decisions to participate in different types of physical activities, along with the time spent in these activities (e.g., LW and VPA). Doing physical activity, regardless of type, is better than doing no physical activity in terms of improved health (Sattelmair et al., 2011), thus our findings might suggest that 
improving perceptions of the built environment has the potential to increase participation and time spent in different types of physical activity to be able to provide health benefits.

Congruent with our findings, previous studies have found associations between walkability subscales and participation and duration in TW, LW, as well as moderate-to-vigorous intensity physical activity (Adlakha et al., 2018; Brownson et al., 2001; Cerin et al., 2014; Cerin et al., 2007; Ding et al., 2013; Evenson et al., 2012; Hoehner et al., 2005; Jáuregui et al., 2016; Jáuregui et al., 2017; Kamada et al., 2009; Kerr et al., 2016; Malambo et al., 2017; Rees-Punia et al., 2018; Sugiyama et al., 2014; Van Dyck et al., 2012; Van Dyck et al., 2013; Zhou et al., 2013). Similarly, this previous research suggests certain walkability subscales are consistently associated with participation or time spent in TW, namely residential density, land use mix diversity, land use mix access, and aesthetics (Hoehner et al., 2005; Kerr et al., 2016; Malambo et al., 2017; Van Dyck et al., 2012). This previous evidence, like our findings, suggests aesthetics is associated with participation or time spent in LW (Jáuregui et al., 2017; Malambo et al., 2017; Sugiyama et al., 2014). Unlike studies elsewhere, our findings suggest that lack of parking at shopping areas was positively associated with participation and time spent in TW. Presumably, lack of parking at shopping areas could encourage people to walk to local shopping areas rather than travel by motor vehicle. In contrast to previous studies (Bergman et al., 2009; Brownson et al., 2001; Rees-Punia et al., 2018; Sugiyama et al., 2014; Van Dyck et al., 2015), we found that crime safety, hilliness, and physical barriers were associated with higher odds of participation or higher weekly minutes of physical activity. Previous physical activity-built environment research has suggested that there is a mismatch between perceptions of the built environment and actual built environment features (Arvidsson et al., 2012; Gebel et al., 2009). More precisely, people living in high walkable neighbourhoods sometimes perceive their neighbourhoods to be less walkable. Conversely, people living in low walkable neighbourhoods sometimes perceive their neighbourhoods to be high walkable (Arvidsson et al., 2012; Gebel et al., 2009). However, perceptions of the built environment is somewhat informed by previous experiences and interactions with the environment. Positive associations between perceived crime safety, hilliness, and physical barriers might reflect the participant's engagement and knowledge of their neighbourhood resulting from them being physically active in their neighbourhoods (reverse causality) rather than 
perceptions causing physical activity. Interventions designed to improve perceptions of overall walkability or even of specific aspects of the built environment (e.g., land uses, aesthetics, or lack of parking at shopping areas) could increase physical activity and improve health of neighbourhood residents.

Like previous studies (Jáuregui et al., 2016; Pelclová et al., 2014; Spence et al., 2006; Van Dyck et al., 2012; Van Dyck et al., 2013; Van Dyck et al., 2015), we found that sex-related effect modification of the associations between neighbourhood characteristics and physical activity were dependent on type of physical activity examined. This previous evidence, like our findings, indicates that street connectivity and crime safety are associated with physical activity among men (Jáuregui et al., 2016; Pelclová et al., 2014). Previous research has shown that overall walkability is associated with duration of transport-related walking among men and women (Van Dyck et al., 2012). However, our findings are indicative of the associations of overall walkability with participation in LW among men and women. Our research is also indicative of the association of overall walkability with VPA minutes among women. Our findings are important as they suggest that while interventions to improve perceptions of the built environment could increase physical activity, the effects of some (i.e., street connectivity, pedestrian infrastructure, or crime safety) or combined interventions (i.e., overall walkability) may differ for men and women.

The large sample size of this study is a strength as it provided sufficient statistical power to undertake analysis. Notably, our sample included participants recruited across an entire province exhibiting different urban geographical locations, and sociodemographic and health-related profiles, thus improving external validity. Our estimates of associations between overall walkability and walkability subscales with different types of physical activity was also an important contribution. Despite these strengths, our study had several limitations. Given the crosssectional analysis, we cannot infer causality. Further, while our models were adjusted for sociodemographic characteristics, data were not available to control for residential self-selection (Cao et al., 2009; McCormack and Shiell, 2011). Notably, prior research suggest that self-selection bias 
might only have a small effect on estimated associations between built environment and physical activity (James et al., 2015). Despite using the Long Form of IPAQ, self-reported physical activity is often over-reported (Hagstromer et al., 2010). It was also not possible to determine whether physical activity occurred in the neighbourhood. We made an assumption that participants reported general perceptions of walkability by not taking into account the effect of seasons on physical activity. The NEWS did not capture features of the built environment related or affected by weather or season (e.g., snow or ice covered sidewalks) which could impact physical activity. The lack of agreement between self-report and objective measures of the built environment (Arvidsson et al., 2012; Gebel et al., 2009), means our findings might only be applicable to interventions designed to modify perceptions of the built environment (e.g., geographic information system walking maps to promote physical activity (McNeill and Emmons, 2012)). Our novel research findings are the associations of lack of parking at shopping areas with participation and time spent in $\mathrm{TW}$, overall walkability with participation in LW, and overall walkability with VPA minutes among women only. Future researchers could determine whether perceptions of different neighbourhood built characteristics are associated with participation and/or time spent in MPA.

In conclusion, overall perceived neighbourhood walkability can be a mechanism for encouraging participation and time spent in different types of physical activity among Albertan men and women. Moreover, improving some or multiple perceptions of neighbourhood walkability, possibly through modifying the neighbourhood built environment or through health promotion and

education interventions that consider sex differences (e.g., crime safety in men and aesthetics in women) (Adams and Sherar, 2018), could also influence participation and time spent in different types of physical activity among Albertan adults.

\section{Acklowledgements}

Alberta's Tomorrow Project is only possible due to the commitment of its research participants, its staff and its funders: Alberta Health and the Alberta Cancer Prevention Legacy Fund, Alberta 
Cancer Foundation, Canadian Partnership Against Cancer and substantial in kind funding from Alberta Health Services. The views expressed herein represent the views of the authors and not of the ATP or any of its funders.

\section{Author contributions}

GM conceived the study. GM, JV and CF obtained funding for this research. CF was involved in the original ATP study design and data collection. VN analyzed the data, interpreted the results, and drafted the initial manuscript. GM, CC, JV, CF interpreted the results and contributed to manuscript drafts. All authors read and approved the final manuscript.

\section{Funding}

This work was supported by the Canadian Institutes of Health Research [FDN-154331]. VN is supported by an O'Brien Institute of Public Health Postdoctoral Scholarship and a Cumming School of Medicine Postdoctoral Scholarship (University of Calgary).

\section{Conflict of interest statement}

All authors have no conflict of interest. 


\section{References}

Adams, E.J., Sherar, L.B., 2018. Community perceptions of the implementation and impact of an intervention to improve the neighbourhood physical environment to promote walking for transport: a qualitative study. BMC Public Health 18:714. https://doi.org/10.1186/s12889018-5619-y.

Adlakha, D., Hipp, J.A., Sallis, J.F., Brownson, R.C., 2018. Exploring Neighbourhood Environments and Active Commuting in Chennai, India. International Journal of Environmental Research and Public Health 15:1840.

Alberta-Parks, 2015. Natural Regions and Sub regions of Alberta. A Framework for Alberta's Parks., Alberta, p. 72.

Arvidsson, D., Kawakami, N., Ohlsson, H., Sundquist, K., 2012. Physical activity and concordance between objective and perceived walkability. Medicine and Science in Sports and Exercise 44:280-7.

ATP, 2018. The Tomorrow Project: Survey 2008. Available from https://www.myatp.ca/wpcontent/uploads/2017/10/Survey2008_V1_Apr2008.pdf [accessed on 10 December 2018].

Bergman, P., Grjibovski, A.M., Hagströmer, M., Sallis, J.F., Sjöström, M., 2009. The association between health enhancing physical activity and neighbourhood environment among Swedish adults - a population-based cross-sectional study. The International Journal of Behavioral Nutrition and Physical Activity 6:8.

Brownson, R.C., Baker, E.A., Housemann, R.A., Brennan, L.K., Bacak, S.J., 2001. Environmental and Policy Determinants of Physical Activity in the United States. American Journal of Public Health 91:1995-2003.

Canada-Guide, 2019. Canadian Geography. Available from http://www.thecanadaguide.com/places/geography/ [accessed on 17 September 2019].

Cao, X., Mokhtarian, P.L., Handy, S.L., 2009. The relationship between the built environment and nonwork travel: A case study of Northern California. Transportation Research Part A: Policy and Practice 43:548-59.

Cerin, E., Cain, K.L., Conway, T.L., Van Dyck, D., Hinckson, E., Schipperijn, J., De Bourdeaudhuij, I., Owen, N., Davey, R.C., et al., 2014. Neighbourhood environments and objectively measured physical activity in 11 countries. Medicine and Science in Sports and Exercise 46 (12):2253-64. 
Cerin, E., Conway, T.L., Adams, M.A., Barnett, A., Cain, K.L., Owen, N., Christiansen, L.B., van Dyck, D., Mitáš, J., et al., 2018. Objectively-assessed neighbourhood destination accessibility and physical activity in adults from 10 countries: An analysis of moderators and perceptions as mediators. Social Science and Medicine 211:282-93.

Cerin, E., Saelens, B.E., Sallis, J.F., Frank, L.D., 2006. Neighbourhood Environment Walkability Scale: Validity and Development of a Short Form. Medicine and Science in Sports and Exercise 38:1682-91.

Cerin, E., Leslie, E., Toit, L.d., Owen, N., Frank, L.D., 2007. Destinations that matter: Associations with walking for transport. Health \& Place 13:713-24.

Christiansen, L.B., Cerin, E., Badland, H., Kerr, J., Davey, R., Troelsen, J., van Dyck, D., Mitáš, J., Schofield, G., et al., 2016. International comparisons of the associations between objective measures of the built environment and transport-related walking and cycling: IPEN Adult Study. Journal of Transport and Health 3:467-78.

Craig, C.L., Marshall, A.L., Sjöström, M., Bauman, A.E., Booth, M.L., Ainsworth, B.E., Pratt, M., Ekelund, U., Yngve, A., et al., 2003. International Physical Activity Questionnaire: 12Country Reliability and Validity. Medicine and Science in Sports and Exercise 35:138195.

De Bourdeaudhuij, I., Van Dyck, D., Salvo, D., Davey, R., Reis, R.S., Schofield, G., Sarmiento, O.L., Mitas, J., Christiansen, L.B., et al., 2015. International study of perceived neighbourhood environmental attributes and Body Mass Index: IPEN Adult study in 12 countries. The International Journal of Behavioral Nutrition and Physical Activity 12:62.

Ding, D., Adams, M.A., Sallis, J.F., Norman, G.J., Hovell, M.F., Chambers, C.D., Hofstetter, C.R., Bowles, H.R., Hagströmer, M., et al., 2013. Perceived neighbourhood environment and physical activity in 11 countries: Do associations differ by country? International Journal of Behavioral Nutrition and Physical Activity 10:57.

Duncan, M.J., Spence, J.C., Mummery, W.K., 2005. Perceived environment and physical activity: a meta-analysis of selected environmental characteristics. The International Journal of Behavioral Nutrition and Physical Activity 2:11.

Evenson, K.R., Block, R., Diez Roux, A.V., McGinn, A.P., Wen, F., Rodríguez, D.A., 2012. Associations of adult physical activity with perceived safety and police-recorded crime: 
the Multi-ethnic Study of Atherosclerosis. The international journal of behavioral nutrition and physical activity 9:146-46.

Farkas, B., Wagner, D.J., Nettel-Aguirre, A., Friedenreich, C., McCormack, G.R., 2019. Evidence synthesis - A systematized literature review on the associations between neighbourhood built characteristics and walking among Canadian adults. Health Promotion and Chronic Disease Prevention in Canada 39:1-14.

Gebel, K., Bauman, A., Owen, N., 2009. Correlates of Non-Concordance between Perceived and Objective Measures of Walkability. Annals of Behavioral Medicine 37:228-38.

Guthold, R., Stevens, G., Riley, L., Bull, F., 2018. Worldwide trends in insufficient physical activity from 2001 to 2016: a pooled analysis of 358 population-based surveys with 1.9 million participants. The Lancet Global Health 6:e1077-86. http://dx.doi.org/10.1016/ S2214-109X(18)30357-7.

Hagstromer, M., Ainsworth, B., Oja, P., and Sjostrom, M., 2010. Comparison of a subjective and an objective measure of physical activity in a population sample. Journal of Physical Activity and Health 7:541-50.

Hands B, P.H., Larkin D, Cantell M, Rose E, 2016. Male and Female Differences in Health Benefits Derived from Physical Activity: Implications for Exercise Prescription. Journal of Women Health, Issues and Care 5.

Hoehner, C.M., Brennan Ramirez, L.K., Elliott, M.B., Handy, S.L., Brownson, R.C., 2005. Perceived and objective environmental measures and physical activity among urban adults. American Journal of Preventive Medicine 28:105-16.

Jack, E., McCormack, G.R., 2014. The associations between objectively-determined and selfreported urban form characteristics and neighbourhood-based walking in adults. The International Journal of Behavioral Nutrition and Physical Activity 11:71.

James, P., Hart, J.E., Arcaya, M.C., Feskanich, D., Laden, F., Subramanian, S.V., 2015. Neighbourhood Self-Selection: The Role of Pre-Move Health Factors on the Built and Socioeconomic Environment. International Journal of Environmental Research and Public Health 12:12489-12504.

Jáuregui, A., Salvo, D., Lamadrid-Figueroa, H., Hernández, B., Rivera, J.A., Pratt, M., 2017. Perceived neighbourhood environmental attributes associated with leisure-time and transport physical activity in Mexican adults. Preventive Medicine 103:S21-S26. 
Jáuregui, A., Pratt, M., Lamadrid-Figueroa, H., Hernández, B., Rivera, J.A., Salvo, D., 2016. Perceived Neighbourhood Environment and Physical Activity: The International Physical Activity and Environment Network Adult Study in Mexico. American Journal of Preventive Medicine 51:271-79.

Kamada, M., Kitayuguchi, J., Inoue, S., Kamioka, H., Mutoh, Y., Shiwaku, K., 2009. Environmental correlates of physical activity in driving and non-driving rural Japanese women. Preventive Medicine 49:490-96.

Kerr, J., Emond, J.A., Badland, H., Reis, R., Sarmiento, O., Carlson, J., Sallis, J.F., Cerin, E., Cain, K., et al., 2016. Perceived Neighbourhood Environmental Attributes Associated with Walking and Cycling for Transport among Adult Residents of 17 Cities in 12 Countries: The IPEN Study. Environmental Health Perspectives 124(3) :290-298.

Lounassalo, I., Salin, K., Kankaanpää, A., Hirvensalo, M., Palomäki, S., Tolvanen, A., Yang, X., Tammelin, T.H., 2019. Distinct trajectories of physical activity and related factors during the life course in the general population: a systematic review. BMC Public Health 19:271.

Malambo, P., Kengne, A.P., Lambert, E.V., De Villers, A., Puoane, T., 2017. Association between perceived built environmental attributes and physical activity among adults in South Africa. BMC Public Health 17:213.

McCormack, G.R., Friedenreich, C., Shiell, A., Giles-Corti, B., Doyle-Baker, P.K., 2010. Sex- and age-specific seasonal variations in physical activity among adults. Journal of Epidemiology and Community Health 64:1010.

McCormack, G.R., Shiell, A., 2011. In search of causality: a systematic review of the relationship between the built environment and physical activity among adults. The International Journal of Behavioral Nutrition and Physical Activity 8:125.

McNeill, L.H., Emmons, K., 2012. GIS walking maps to promote physical activity in low-income public housing communities: a qualitative examination. Preventing Chronic Disease 9: 110086. http://dx.doi.org/10.5888/pcd9.110086.

Pelclová, J., Frömel, K., Cuberek, R., 2014. Gender-Specific Associations between Perceived Neighbourhood Walkability and Meeting Walking Recommendations When Walking for Transport and Recreation for Czech Inhabitants over 50 Years of Age. International Journal of Environmental Research and Public Health 11:527-36. 
Rees-Punia, E., Hathaway, E.D., Gay, J.L., 2018. Crime, perceived safety, and physical activity: A meta-analysis. Preventive Medicine 111:307-13.

Robson, P.J., Solbak, N.M., Haig, T.R., Whelan, H.K., Vena, J.E., Akawung, A.K., Rosner, W.K., Brenner, D.R., Cook, L.S., et al., 2016. Design, methods and demographics from phase I of Alberta's Tomorrow Project cohort: a prospective cohort profile. CMAJ OPEN 4:E515E27.

Sallis, J.F., 2011. Scoring for the Neighbourhood Environment Walkability Scale - Abbreviated (NEWS-A). Available from http://sallis.ucsd.edu/Documents/Measures_documents/NEWS_A_scoring.pdf [accessed on 25 October 2018].

Sallis, J.F., Cerin, E., Conway, T.L., Adams, M.A., Frank, L.D., Pratt, M., Salvo, D., Schipperijn, J., Smith, G., et al., 2016. Physical activity in relation to urban environments in 14 cities worldwide: a cross-sectional study. The Lancet 387:2207-17.

Sattelmair, J., Pertman, J., Ding Eric, L., Kohl Harold, W., Haskell, W., Lee, I.M., 2011. Dose Response Between Physical Activity and Risk of Coronary Heart Disease. Circulation 124 (7):789-795.

Shifan, D., Dianna, D.C., Kathleen, B.W., Prabasaj, P., Susan, A.C., Janet, E.F., 2015. Participation in Types of Physical Activities among US Adults-National Health and Nutrition Examination Survey 1999-2006. Journal of Physical Activity and Health 12:S128-S40.

Spence, J.C., Plotnikoff, R.C., Rovniak, L.S., Ginis, K.A., Rodgers, W., Lear, S.A., 2006. Perceived Neighbourhood Correlates of Walking Among Participants Visiting the "Canada on the Move" Website. Canadian Journal of Public Health / Revue Canadienne de Sante'e Publique 97:S36-S40.

Stat-Can., 2003. Postal Code Conversion File (PCCF), Reference Guide. Available from http://publications.gc.ca/Collection/Statcan/92F0153GIE/92F0153GIE2003001.pdf [accessed on 09 September 2019].

Stat-Can, 2018. Canada's rural population since 1851. Available from https://www12.statcan.gc.ca/census-recensement/2011/as-sa/98-310-x/98-310x2011003_2-eng.cfm [accessed on 27 September 2019]. 
Sugiyama, T., Cerin, E., Owen, N., Oyeyemi, A.L., Conway, T.L., Van Dyck, D., Schipperijn, J., Macfarlane, D.J., Salvo, D., et al., 2014. Perceived neighbourhood environmental attributes associated with adults' recreational walking: IPEN Adult study in 12 countries. Health and Place 28:22-30.

Travel-Alberta., 2019. Weather \& Climate. Available from https://www.travelalberta.com/ca/plan-your-trip/weather-climate/ [accessed on 11 September 2019].

Tucker, P., Gilliland, J., 2007. The effect of season and weather on physical activity: A systematic review. Public Health 121:909-22.

Van Dyck, D., Cerin, E., Conway, T.L., De Bourdeaudhuij, I., Owen, N., Kerr, J., Cardon, G., Frank, L.D., Saelens, B.E., et al., 2012. Perceived neighbourhood environmental attributes associated with adults' transport-related walking and cycling: Findings from the USA, Australia and Belgium. The International Journal of Behavioral Nutrition and Physical Activity 9:70.

Van Dyck, D., Cerin, E., Conway, T.L., De Bourdeaudhuij, I., Owen, N., Kerr, J., Cardon, G., Frank, L.D., Saelens, B.E., et al., 2013. Perceived neighbourhood environmental attributes associated with adults' leisure-time physical activity: findings from Belgium, Australia and the USA. Health and Place 19:59-68.

Van Dyck, D., Cerin, E., De Bourdeaudhuij, I., Salvo, D., Christiansen, L.B., Macfarlane, D., Owen, N., Mitas, J., Troelsen, J., et al., 2015. Moderating effects of age, gender and education on the associations of perceived neighbourhood environment attributes with accelerometer-based physical activity: The IPEN adult study. Health and Place 36:65-73.

Wendel-Vos, W., Droomers, M., Kremers, S., Brug, J., Van Lenthe, F., 2007. Potential environmental determinants of physical activity in adults: a systematic review. Obesity Reviews 8:425-440.

Ye, M., Robson, P.J., Eurich, D.T., Vena, J.E., Xu, J.-Y., Johnson, J.A., 2017. Cohort Profile: Alberta's Tomorrow Project. International Journal of Epidemiology 46:1097-981.

Zhou, R., Li, Y., Umezaki, M., Ding, Y., Jiang, H., Comber, A., Fu, H., 2013. Association between physical activity and neighbourhood environment among middle-aged adults in Shanghai. Journal of Environmental and Public Health 2013:239595. http://dx.doi.org/10.1155/2013/239595. 
Table 1: Demographics and health-related characteristics of participants of Alberta's Tomorrow Project $(n=14,078)$

\begin{tabular}{|c|c|}
\hline Demographics and health-related characteristics & $\%$ \\
\hline \multicolumn{2}{|l|}{ Age (years) } \\
\hline 35 to $<45$ & 15.0 \\
\hline 45 to $<55$ & 37.9 \\
\hline 55 to $<65$ & 30.1 \\
\hline$\geq 65$ & 17.0 \\
\hline \multicolumn{2}{|l|}{ Sex } \\
\hline Male & 38.5 \\
\hline Female & 61.5 \\
\hline \multicolumn{2}{|l|}{ Self-reported health } \\
\hline Poor or fair & 7.6 \\
\hline Good & 34.1 \\
\hline Very good & 41.0 \\
\hline Excellent & 17.3 \\
\hline \multicolumn{2}{|l|}{ Marital status } \\
\hline Married or not married, but living with someone & 77.1 \\
\hline Separated or divorced & 12.5 \\
\hline Widowed & 4.4 \\
\hline Single, never married & 6.0 \\
\hline
\end{tabular}




\begin{tabular}{ll}
\hline Number of children living in the household & 72.5 \\
0 & 12.1 \\
1 & 11.4 \\
2 & 4.0 \\
$\geq 3$ & 22.3 \\
\hline Highest education level & 38.5 \\
Completed some or entire high school & 26.2 \\
Completed some or entire technical college training & 13.0 \\
Completed some or entire university degree & \\
Completed some or entire university post-graduate degree & 54.1 \\
\hline Employment status & 14.4 \\
Working full-time & 6.3 \\
Working part-time & 20.4 \\
Home maker & 4.8 \\
Retired & \\
Other or not employed or student & \\
\hline
\end{tabular}




\begin{tabular}{ll}
\hline Household income (Canadian Dollars) & \\
$\$ 0$ to 49,999 & 18.5 \\
$\$ 50,000$ to 99,999 & 31.7 \\
$\$ 100,000$ to 149,999 & 23.2 \\
$\$ 150,000$ to 199,999 & 9.6 \\
$\$ 200,000$ to 250,999 & 4.1 \\
$\$ \geq 251,000$ & 5.4 \\
Did not answer & 7.5 \\
\hline Season of receipt of the HLQ & 19.2 \\
Winter & 4.3 \\
Spring & 25.5 \\
Summer & 51.0 \\
Fall
\end{tabular}

Abbreviation: HLQ=Health and Lifestyle Questionnaire 
Table 2: Neighbourhood characteristics of participants in Alberta's Tomorrow Project $(\mathbf{n = 1 4 , 0 7 8 )}$

\begin{tabular}{llc}
\hline NEWS-A subscales ${ }^{\wedge}$ & Cronbach's alpha ( $\boldsymbol{\alpha})$ & Mean scores $\dagger$ \\
\hline Residential density (6 questions) & 0.73 & $201.6(\mathrm{SD}=50.7)$ \\
Land use mix diversity (20 questions) & 0.94 & $2.5(\mathrm{SD}=0.9)$ \\
Land use mix access (3 questions) & 0.75 & $2.9(\mathrm{SD}=0.9)$ \\
Street connectivity (3 questions) & 0.44 & $2.7(\mathrm{SD}=0.8)$ \\
Pedestrian infrastructure (6 questions) & 0.79 & $2.9(\mathrm{SD}=0.7)$ \\
Aesthetics (4 questions) & 0.75 & $3.0(\mathrm{SD}=0.7)$ \\
Traffic safety (3 questions) & 0.54 & $2.6(\mathrm{SD}=0.5)$ \\
Crime safety (3 questions) & 0.78 & $3.5(\mathrm{SD}=0.6)$ \\
Hilliness (1 question) & - & $3.6(\mathrm{SD}=0.8)$ \\
Physical barriers (1 question) & - & $3.7(\mathrm{SD}=0.8)$ \\
Lack of parking at shopping areas (1 question) & - & $1.6(\mathrm{SD}=0.9)$ \\
Overall walkability & 0.94 & $0.01(\mathrm{SD}=4.4)$
\end{tabular}

Abbreviations: NEWS-A=neighbourhood environment walkability scale abbreviated version and SD=standard deviation

$\wedge=$ minimum possible scores are 173 (residential density), 1 (land use mix diversity), 1 (land use mix access), 1 (street connectivity), 1 (pedestrian infrastructure), 1 (aesthetics), 1 (traffic safety), 1 (crime safety), 1 (hilliness), 1 (physical barriers), 1 (lack of parking at shopping areas) and -25.9 (overall walkability)

$\wedge$ =maximum possible scores are 865 (residential density), 5 (land use mix diversity), 4 (land use mix access), 4 (street connectivity), 4 (pedestrian infrastructure), 4 (aesthetics), 4 (traffic safety), 4 (crime safety), 4 (hilliness), 4 (physical barriers), 4 (lack of parking at shopping areas) and 26.1 (overall walkability)

$\dagger=$ values in parentheses represent actual SDs 
Table 3: Physical activity participation and duration in the previous week in Alberta's Tomorrow Project participants

\begin{tabular}{|c|c|c|}
\hline & $\begin{array}{c}\text { Participation } \\
\%\end{array}$ & $\begin{array}{c}\text { Minutes/week } \dagger \\
\text { Mean }\end{array}$ \\
\hline Participation in transportation walking $(n=14,078)$ & 60.8 & - \\
\hline Participation in leisure walking $(n=14,078)$ & 60.8 & - \\
\hline Duration of leisure walking $(\mathrm{n}=\mathbf{8 , 5 3 5})^{\#}$ & - & $194.1(\mathrm{SD}=206.6)$ \\
\hline Duration of moderate-intensity physical activity $(n=3,980)^{\#}$ & - & $166.9(\mathrm{SD}=177.4)$ \\
\hline Participation in vigorous-intensity physical activity $(n=14,078)$ & 32.9 & - \\
\hline Duration of vigorous-intensity physical activity $(n=4,595)^{\#}$ & - & $181.1(\mathrm{SD}=157.1)$ \\
\hline
\end{tabular}


Table 4: Associations between overall walkability and walkability subscales with physical activity participation and duration in the last week, in Alberta's Tomorrow Project participants

\begin{tabular}{|c|c|c|c|c|c|c|c|c|}
\hline \multicolumn{5}{|c|}{ Participation } & \multicolumn{4}{|c|}{ Minutes/week } \\
\hline & $\begin{array}{c}\text { TW } \\
(n=14,078)\end{array}$ & $\begin{array}{c}\text { LW } \\
(n=14,078)\end{array}$ & $\begin{array}{c}\text { MPA } \\
(n=14,078)\end{array}$ & $\begin{array}{c}\text { VPA } \\
(n=14,078)\end{array}$ & $\begin{array}{c}\text { TW } \\
(\mathrm{n}=\mathbf{8 , 4 7 8})^{\#}\end{array}$ & $\begin{array}{c}\text { LW } \\
(\mathrm{n}=\mathbf{8 , 5 3 5})^{\#}\end{array}$ & $\begin{array}{c}\text { MPA } \\
(\mathrm{n}=\mathbf{3 , 9 8 0})^{\#}\end{array}$ & $\begin{array}{c}\text { VPA } \\
(n=4,595)^{\#}\end{array}$ \\
\hline $\begin{array}{l}\text { Walkability } \\
\text { variables }\end{array}$ & $\begin{array}{c}\text { OR } \\
(95 \% \mathrm{CI})^{\mathrm{ac}}\end{array}$ & $\begin{array}{c}\text { OR } \\
(95 \% \mathrm{CI})^{\mathrm{ac}}\end{array}$ & $\begin{array}{c}\text { OR } \\
(95 \% \mathrm{CI})^{\mathrm{ac}}\end{array}$ & $\begin{array}{c}\text { OR } \\
(95 \% \mathrm{CI})^{\mathrm{ac}}\end{array}$ & $\begin{array}{c}\beta \\
(95 \% \mathrm{CI})^{\mathrm{bc}}\end{array}$ & $\begin{array}{c}\beta \\
(95 \% \mathbf{C I})^{b c}\end{array}$ & $\begin{array}{c}\beta \\
(95 \% \mathrm{CI})^{\mathrm{bc}}\end{array}$ & $\begin{array}{c}\beta \\
(95 \% \mathbf{C I})^{b c}\end{array}$ \\
\hline Overall & 1.05 & 1.03 & 1.02 & 1.02 & 1.41 & 1.01 & 0.61 & 1.37 \\
\hline walkability & $(1.04,1.06)^{*}$ & $(1.02,1.04)^{*}$ & $(1.01,1.03)^{*}$ & $(1.01,1.03)^{*}$ & $(0.43,2.40)^{*}$ & $(0.08,1.94)^{*}$ & $(-0.46,1.69)$ & $(0.39,2.35)^{*}$ \\
\hline $\begin{array}{l}\text { Residential } \\
\text { density }\end{array}$ & $\begin{array}{c}1.25 \\
(1.19,1.30)^{*}\end{array}$ & $\begin{array}{c}1.04 \\
(1.01,1.08)^{*}\end{array}$ & $\begin{array}{c}1.004 \\
(0.97,1.04)\end{array}$ & $\begin{array}{c}0.99 \\
(0.96,1.04)\end{array}$ & $\begin{array}{c}4.72 \\
(0.61,8.84)^{*}\end{array}$ & $\begin{array}{c}-1.72 \\
(-5.50,2.07)\end{array}$ & $\begin{array}{c}2.55 \\
(-2.42,7.52)\end{array}$ & $\begin{array}{c}6.92 \\
(1.67,12.18)^{*}\end{array}$ \\
\hline $\begin{array}{l}\text { Land use } \\
\text { mix diversity }\end{array}$ & $\begin{array}{c}1.22 \\
(1.17,1.26)^{*}\end{array}$ & $\begin{array}{c}1.09 \\
(1.05,1.13)^{*}\end{array}$ & $\begin{array}{c}1.08 \\
(1.04,1.12)^{*}\end{array}$ & $\begin{array}{c}1.12 \\
(1.08,1.16)^{*}\end{array}$ & $\begin{array}{c}1.61 \\
(-2.85,6.07)\end{array}$ & $\begin{array}{c}2.46 \\
(-1.51,6.43)\end{array}$ & $\begin{array}{c}-0.76 \\
(-6.06,4.55)\end{array}$ & $\begin{array}{c}5.73 \\
(1.25,10.20)^{*}\end{array}$ \\
\hline $\begin{array}{l}\text { Land use } \\
\text { mix access }\end{array}$ & $\begin{array}{c}1.30 \\
(1.25,1.34)^{*}\end{array}$ & $\begin{array}{c}1.14 \\
(1.10,1.18)^{*}\end{array}$ & $\begin{array}{c}1.06 \\
(1.02,1.11)^{*}\end{array}$ & $\begin{array}{c}1.12 \\
(1.08,1.16)^{*}\end{array}$ & $\begin{array}{c}5.75 \\
(1.37,10.13)^{*}\end{array}$ & $\begin{array}{c}3.87 \\
(-0.05,7.78)\end{array}$ & $\begin{array}{c}2.12 \\
(-2.87,7.12)\end{array}$ & $\begin{array}{c}9.40 \\
(5.12,13.69)^{*}\end{array}$ \\
\hline $\begin{array}{l}\text { Street } \\
\text { connectivity }\end{array}$ & $\begin{array}{c}1.07 \\
(1.04,1.11)^{*}\end{array}$ & $\begin{array}{c}1.02 \\
(0.98,1.05)\end{array}$ & $\begin{array}{c}1.02 \\
(0.98,1.05)\end{array}$ & $\begin{array}{c}0.99 \\
(0.95,1.03)\end{array}$ & $\begin{array}{c}1.85 \\
(-2.42,6.12)\end{array}$ & $\begin{array}{c}-1.91 \\
(-5.91,2.08)\end{array}$ & $\begin{array}{c}-1.57 \\
(-6.41,3.25)\end{array}$ & $\begin{array}{c}-0.92 \\
(-5.29,3.44)\end{array}$ \\
\hline $\begin{array}{l}\text { Pedestrian } \\
\text { infrastructure }\end{array}$ & $\begin{array}{c}1.11 \\
(1.07,1.15)^{*}\end{array}$ & $\begin{array}{c}1.10 \\
(1.07,1.14)^{*}\end{array}$ & $\begin{array}{c}1.04 \\
(0.99,1.08)\end{array}$ & $\begin{array}{c}1.08 \\
(1.04,1.12)^{*}\end{array}$ & $\begin{array}{c}0.38 \\
(-4.12,4.89)\end{array}$ & $\begin{array}{c}3.13 \\
(-0.73,6.98)\end{array}$ & $\begin{array}{c}2.90 \\
(-1.81,7.6)\end{array}$ & $\begin{array}{c}4.99 \\
(0.58,9.41)^{*}\end{array}$ \\
\hline Aesthetics & $\begin{array}{c}1.15 \\
(1.11,1.19)^{*}\end{array}$ & $\begin{array}{c}1.20 \\
(1.16,1.25)^{*}\end{array}$ & $\begin{array}{c}1.10 \\
(1.06,1.15)^{*}\end{array}$ & $\begin{array}{c}1.11 \\
(1.07,1.16)^{*}\end{array}$ & $\begin{array}{c}8.43 \\
(4.26,12.59)^{*}\end{array}$ & $\begin{array}{c}4.87 \\
(1.08,8.65)^{*}\end{array}$ & $\begin{array}{c}-0.11 \\
(-5.24,5.01)\end{array}$ & $\begin{array}{c}2.70 \\
(-1.56,6.95)\end{array}$ \\
\hline
\end{tabular}




\begin{tabular}{|c|c|c|c|c|c|c|c|c|}
\hline Traffic safety & $\begin{array}{c}0.97 \\
(0.93,0.99)^{*}\end{array}$ & $\begin{array}{c}0.99 \\
(0.95,1.02)\end{array}$ & $\begin{array}{c}1.01 \\
(0.97,1.05)\end{array}$ & $\begin{array}{c}0.96 \\
(0.93,1.003)\end{array}$ & $\begin{array}{c}-2.49 \\
(-6.61,1.63)\end{array}$ & $\begin{array}{c}-3.59 \\
(-7.45,0.26)\end{array}$ & $\begin{array}{c}2.13 \\
(-2.92,7.19)\end{array}$ & $\begin{array}{c}-3.17 \\
(-7.63,1.28)\end{array}$ \\
\hline Crime safety & $\begin{array}{c}0.92 \\
(0.89,0.95)^{*}\end{array}$ & $\begin{array}{c}1.06 \\
(1.02,1.10)^{*}\end{array}$ & $\begin{array}{c}1.04 \\
(0.99,1.08)\end{array}$ & $\begin{array}{c}1.01 \\
(0.97,1.05)\end{array}$ & $\begin{array}{c}-2.34 \\
(-6.79,2.09)\end{array}$ & $\begin{array}{c}-0.05 \\
(-4.31,4.21)\end{array}$ & $\begin{array}{c}1.72 \\
(-3.49,6.94)\end{array}$ & $\begin{array}{c}-3.15 \\
(-7.83,1.53)\end{array}$ \\
\hline Hilliness & $\begin{array}{c}1.01 \\
(0.98,1.05)\end{array}$ & $\begin{array}{c}1.03 \\
(0.99,1.06)\end{array}$ & $\begin{array}{c}0.98 \\
(0.94,1.02)\end{array}$ & $\begin{array}{c}0.99 \\
(0.95,1.03)\end{array}$ & $\begin{array}{c}0.61 \\
(-3.81,5.03)\end{array}$ & $\begin{array}{c}4.60 \\
(0.78,8.42)^{*}\end{array}$ & $\begin{array}{c}-0.65 \\
(-5.39,4.10)\end{array}$ & $\begin{array}{c}-0.56 \\
(-4.88,3.77)\end{array}$ \\
\hline $\begin{array}{l}\text { Physical } \\
\text { barriers }\end{array}$ & $\begin{array}{c}1.01 \\
(0.98,1.05)\end{array}$ & $\begin{array}{c}1.03 \\
(0.99,1.06)\end{array}$ & $\begin{array}{c}0.99 \\
(0.96,1.04)\end{array}$ & $\begin{array}{c}1.02 \\
(0.98,1.06)\end{array}$ & $\begin{array}{c}0.41 \\
(-4.43,5.26)\end{array}$ & $\begin{array}{c}4.13 \\
(0.46,7.80)^{*}\end{array}$ & $\begin{array}{c}-2.57 \\
(-7.96,2.81)\end{array}$ & $\begin{array}{c}-0.38 \\
(-4.45,3.70)\end{array}$ \\
\hline $\begin{array}{l}\text { Lack of } \\
\text { parking at } \\
\text { shopping areas }\end{array}$ & $\begin{array}{c}1.09 \\
(1.05,1.12)^{*}\end{array}$ & $\begin{array}{c}0.97 \\
(0.94,1.01)\end{array}$ & $\begin{array}{c}0.99 \\
(0.96,1.04)\end{array}$ & $\begin{array}{c}0.99 \\
(0.95,1.03)\end{array}$ & $\begin{array}{c}6.91 \\
(2.19,11.62)^{*}\end{array}$ & $\begin{array}{c}1.72 \\
(-2.31,5.76)\end{array}$ & $\begin{array}{c}6.17 \\
(0.81,11.53)^{*}\end{array}$ & $\begin{array}{c}5.62 \\
(1.08,10.15)^{*}\end{array}$ \\
\hline
\end{tabular}

Abbreviations: TW=transportation walking, LW=leisure walking, MPA=moderate-intensity physical activity, VPA=vigorous-intensity physical activity, $\mathrm{OR}=$ odds ratio, $\beta=$ beta coefficient, $\mathrm{CI}=$ confidence interval

\# =only cases with $\geq 10$ minutes of physical activity included in analysis

a=generalized linear regression models estimated by using binomial distributions and logit link functions $\mathrm{b}=$ generalized linear regression models estimated by using gamma distributions and identity link functions $\mathrm{c}=$ generalized linear regression models controlled for age, sex, self-reported general health, marital status, number of children in household, highest education level, employment status, household income, and season of receipt of the HLQs $*=\mathrm{p}$ value $<0.05$ 
Table 5: Sex-interaction analysis of the associations between overall walkability and walkability subscales with physical activity participation and duration in the last week, in Alberta's Tomorrow Project participants

\begin{tabular}{|c|c|c|c|}
\hline $\begin{array}{l}\text { Walkability } \\
\text { variables }\end{array}$ & $\begin{array}{c}\text { Type of physical } \\
\text { activity } \\
(n=14,078)\end{array}$ & $\begin{array}{c}\text { Parameter estimate } \\
\text { for men } \\
\text { OR } \\
(95 \% \mathrm{CI})^{\mathrm{ac}}\end{array}$ & $\begin{array}{c}\text { Parameter estimate } \\
\text { for women } \\
\text { OR } \\
(95 \% \mathrm{CI})^{\mathrm{ac}}\end{array}$ \\
\hline Overall walkability & Participation in LW & $\begin{array}{c}1.005 \\
(1.002,1.008)^{*}\end{array}$ & $\begin{array}{c}1.009 \\
(1.007,1.01)^{*}\end{array}$ \\
\hline Pedestrian infrastructure & Participation in LW & $\begin{array}{c}1.01 \\
(0.99,1.03)\end{array}$ & $\begin{array}{c}1.03 \\
(1.02,1.04)^{*}\end{array}$ \\
\hline $\begin{array}{l}\text { Lack of parking at } \\
\text { shopping areas }\end{array}$ & Participation in MPA & $\begin{array}{c}1.01 \\
(0.99,1.02)\end{array}$ & $\begin{array}{c}0.99 \\
(0.98,1.002)\end{array}$ \\
\hline Street connectivity & Participation in VPA & $\begin{array}{c}0.98 \\
(0.97,0.99)^{*}\end{array}$ & $\begin{array}{c}1.01 \\
(0.99,1.02)\end{array}$ \\
\hline $\begin{array}{l}\text { Walkability } \\
\text { variables }\end{array}$ & $\begin{array}{c}\text { Type of physical } \\
\text { activity } \\
(n=4,595)^{\#}\end{array}$ & $\begin{array}{c}\text { Parameter estimate } \\
\text { for men } \\
\beta \\
(95 \% \text { CI })^{\text {bc }}\end{array}$ & $\begin{array}{c}\text { Parameter estimate } \\
\text { for women } \\
\beta \\
(95 \% \mathrm{CI})^{\mathrm{bc}}\end{array}$ \\
\hline Overall walkability & Minutes of VPA & $\begin{array}{c}-0.19 \\
(-2.05,1.68)\end{array}$ & $\begin{array}{c}2.05 \\
(0.94,3.16)^{*}\end{array}$ \\
\hline
\end{tabular}


Crime safety

Physical barriers
Minutes of VPA

Minutes of VPA
$-10.58$

$(-19.69,-1.46)^{*}$

$-6.13$

$(-13.29,1.03)$
2.86

0.06

$(-5.19,5.31)$

$(-1.92,7.63)$

Abbreviations: LW=leisure walking, MPA=moderate-intensity physical activity, VPA=vigorous-intensity physical activity, OR=odds ratio, $\beta=$ beta coefficient, $\mathrm{CI}=$ confidence interval

$\#=$ only cases with $\geq 10$ minutes of physical activity included in analysis

$\mathrm{a}=$ generalized linear regression models estimated by using binomial distributions and logit link functions

$\mathrm{b}=$ generalized linear regression models estimated by using gamma distributions and identity link functions

$\mathrm{c}=$ generalized linear regression models controlled for age, sex, self-reported general health, marital status, number of children in

household, highest education level, employment status, household income, and season of receipt of the HLQs

$*=\mathrm{p}$ value $<0.05$ 